Gut, 1987, 28, 829-834

\title{
Effects of auranofin and myochrysine on intestinal transport and morphology in the rat
}

\author{
H V AMMON, S A FOWLE, J A CUNNINGHAM, R A KOMOROWSKI, \\ AND R F LOEFFLER
}

From the Department of Medicine and Pathology, VA Medical Center, Milwaukee, Wisconsin, Milwaukee County General Hospital, and the Medical College of Wisconsin, Milwaukee, Wisconsin, USA

SUMMARY Auranofin (SKF-D 39162) is an oral gold preparation for the treatment of rheumatoid arthritis. One of its major side effects is diarrhoea. To determine one possible mechanism for this we compared the effects of auranofin and myochrysine on intestinal water and solute transport in the rat. Jejunal perfusion with $2 \mathrm{mM}$ auranofin $(n=5)$ induced fluid and electrolyte secretion and inhibited glucose absorption $(\mathrm{p}<0.01)$. Auranofin $(0.2 \mathrm{mM})$ induced fluid secretion in the jejunum $(n=5 ; p<0.01)$ and colon $(n=6 ; p<0 \cdot 01)$. In contrast, 2 mM myochrysine enhanced jejunal water and electrolyte absorption $(n=6 ; p<0.02)$. Both compounds enhanced absorption of mannitol $(p<0 \cdot 01)$. Perfusion of $0.2 \mathrm{mM}$ auranofin for two hours had no significant effect on mucosal c-AMP levels $(n=4)$. After perfusion for two hours with $2 \mathrm{mM}$ auranofin the jejunal mucosa showed severe injury by light and scanning electronmicroscopy while myochrysine had no apparent effect. The damage after perfusion with $0.2 \mathrm{mM}$ auranofin for two hours was less severe. Auranofin was more rapidly absorbed than myochrysine $(p<0 \cdot 05)$. These effects provide an explanation for the diarrhoea associated with auranofin therapy.

Auranofin (SKF-D39162) (2,3,4,6 tetra-o-acetyl1 -thio- $\beta$-D-glucopyranosato-S-[triethyl-phospine]gold[I]) is used for oral chrysotherapy of rheumatoid arthritis. ${ }^{1-3} \mathrm{~A}$ well recognised side effect of therapy with auranofin is diarrhoea. ${ }^{1-3}$ The mechanism by which auranofin induces diarrhoea has not been investigated in vivo. Here we report the effects of auranofin on electrolyte and water transport, mucosal permeability and morphology in the rat intestine in comparison with another gold compound, myochrysine (gold-Na-thiomalate).

\section{Methods}

MATERIALS

Auranofin was a gift from Smith Kline and French Laboratories, Philadelphia, PA, myochrysine was purchased from Merck-Sharp and Dohme, West-

Address for correspondence: Helmut V Ammon MD, Division of Gastroenterology, Henry Ford Hospital, 2799 West Grand Boulevard, Detroit, Michigan 48202, USA.

Received for publication 7 November 1986. point, PA, taurocholate from Calbiochem-Behring, La Jolla, CA, egg phosphatidylcholine (Type XI-E) and mannitol from Sigma Chemical Company, St Louis, MO, and $\left[1,2^{-14} \mathrm{C}\right]$ polyethylene glycol $\left({ }^{14} \mathrm{C}\right.$ PEG) and ${ }^{3} \mathrm{H}$-mannitol from New England Nuclear, Boston, MA. All compounds were used as purchased.

\section{PERFUSION TECHNIQUE}

In vivo perfusion experiments were carried out in male Sprague-Dawley rats (King Animal Labs, Oregon, WI) weighing 250-350 g. Forty centimetres of proximal jejunum were isolated and cannulated at the proximal and distal ends under general anaesthesia with phenobarbital after an overnight fast. The intestine was rinsed with control solution (as described below) and returned to the abdominal cavity. The lumen was perfused in a single pass at 42 $\mathrm{ml} /$ hour. For colonic perfusion experiments the cannula was placed immediately distal to the caecum. A rectal catheter was secured after gently cleaning the colon with control solution. The temperature of the perfusion solution was maintained at $37^{\circ} \mathrm{C}$ and 
the body temperature of the animals was kept at $37^{\circ} \mathrm{C}$ with a heat lamp controlled by a thermometer placed in the rectum or abdominal cavity (for the colonic perfusion studies). Control and test solutions were perfused for two hours each. An equilibration period of one hour was followed by three consecutive 20 minute sampling periods.

\section{COMPOSITION OF PERFUSION SOLUTIONS AND}

EXPERIMENTAL DESIGN

Control and test solutions contained (in $\mathrm{mmol} / \mathrm{l}$ ): $\mathrm{NaCl} 125, \mathrm{KCl} 5$, glucose $11 \cdot 2$, mannitol 4 with ${ }^{3} \mathrm{H}$ mannitol $20 \mu \mathrm{Ci} / \mathrm{l}$, Na taurocholate 10 , lecithin 5 , and PEG-4000 $5 \mathrm{~g} / \mathrm{l}$ with ${ }^{14} \mathrm{C}-\mathrm{PEG} 4 \mu \mathrm{Ci} / \mathrm{l}$ as nonabsorbable marker. ${ }^{4}$ Taurocholate and lecithin were used for solubilisation of auranofin. Test solutions contained in addition 0.2 or $2.0 \mathrm{mM}$ auranofin or 2.0 $\mathrm{mM}$ myochrysine. Auranofin was dissolved in pyridine with taurocholate and lecithin in the appropriate molar ratios. Pyridine was removed in a rotary evaporator and the precipitate dissolved in an aqueous solution which contained the remaining constituents of the test solutions. $0.2 \mathrm{mM}$ auranofin formed a stable solution. The solution containing $2 \mathrm{mM}$ auranofin formed a precipitate after about 30 minutes. Therefore, a fresh solution of auranofin was prepared every 30 minutes. Bottles containing auranofin were wrapped with aluminium foil to avoid exposure to light. The perfusion sequence was always control test.

To determine whether perfusion with auranofin affected mucosal c-AMP levels, two adjacent loops of $30 \mathrm{~cm}$ jejunum were perfused at $30 \mathrm{ml} / \mathrm{h}$. Control and test solutions were perfused for two hours in the sequence control-control (control loop) or controltest (test loop). The assignment of the control or test loop to the proximal and distal segment was alternated. At the conclusion of the perfusion studies, mucosal c-AMP content was determined in each loop.

\section{ANALYTICAL METHODS}

For isotope determinations $1.0 \mathrm{ml}$ perfusion solution or sample was mixed with $10 \mathrm{ml}$ of a scintillation cocktail (Ready-Solv HP, Beckman Instruments, Fullerton, CA) and counted in a liquid scintillation counter (Beckman LS-255). Quench correction was made by external standardisation. Counts per minute were converted to disintegrations per minute with a computer program which corrected for quenching and spillover of ${ }^{14} \mathrm{C}$ into the tritum channel. ${ }^{5}$ Spillover of tritium into the ${ }^{14} \mathrm{C}$ channel was $<1 \%$. Sodium and potassium were determined by flame photometry, chloride by electrometric titration with a silver nitrate solution, osmolarity by freezing point depression, glucose by the glucose oxidase method
(Boehringer), auranofin and myochrysine as elemental gold by atomic absorption spectroscopy on a Varian atomic absorption spectrometer (Varian Model AA 1475; Varian Instrument Group, Sunnyvale, CA). Bicarbonate was calculated as the anion gap between sodium, potassium and chloride. ${ }^{6}$ For the c-AMP assay control and test loops were rinsed with a solution containing $8 \mathrm{mM}$ theophylline in $0 \cdot 1 \mathrm{M}$ tris buffer, $\mathrm{pH} 7 \cdot 4$. The mucosa was scraped with a glass slide and frozen in liquid nitrogen and stored at $-70^{\circ} \mathrm{C} .50$ to $100 \mathrm{mg}$ of frozen tissue were placed in $8 \mathrm{ml} 6 \%$ trichloroacetic acid with $0 \cdot 1 \mu \mathrm{Ci}{ }^{3} \mathrm{H}$ c-AMP as recovery marker, homogenized, centrifuged, and the supernatant extracted with ether.' Protein in the precipitate was determined by the method of Lowry. ${ }^{8}$ c-AMP was determined in duplicate in the supernatant with a commercial radioimmunoassay kit (Biomedical Technologies, Cambridge, MA) based on the radioimmunoassay of Harper and Brooker.'

\section{MORPHOLOGICAL STUDIES}

After completion of the perfusion experiments tissue samples from the central portion of the perfused segment were fixed in $10 \%$ buffered formalin for light microscopy, and in $2.6 \%$ glutaraldehyde in $0.1 \mathrm{M}$ phosphate buffer ( $\mathrm{pH} \mathrm{7.4)}$ for scanning electron microscopy. Haematoxylineosin stains were used for light microscopic studies. For scanning electron microscopy the specimens were dehydrated by serial passage through $30,50,75$, and $95 \%$ ethanol solutions for 30 minutes. Subsequently they underwent critical point drying with $\mathrm{CO}_{2}$ followed by carbon coating in a vacuum chamber. The specimens were examined with a scanning electron microscope (AMRAY Model 1200, Bedford, MA) using $15 \mathrm{KV}$ and a spot size of 4 .

CALCULATIONS AND STATISTICAL ANALYSIS

Net water and solute movements were calculated by standard formulae from the changes in PEG and solute concentrations. ${ }^{5}$ The results are expressed as mean $\pm S E$. The mean of three consecutive 20 minute collection periods during the perfusion experiments constitutes one data point. Differences in the net movement of solutes and water and c-AMP concentrations were statistically evaluated by paired or unpaired $t$-tests.

\section{Results}

EFFECTS OF AURANOFIN ON INTESTINAL TRANSPORT (Table 1)

Auranofin $(0 \cdot 2 \mathrm{mM})$ induced fluid secretion in the jejunum $(n=5 ; p<0 \cdot 01)$ and colon $(n=6 ; p<0 \cdot 01)$. In addition, it enhanced the absorption of mannitol; this 
Table 1 Effect of auranofin on intestinal water and solute transport in the rat

\begin{tabular}{|c|c|c|c|}
\hline $\begin{array}{l}\text { Net transport } \\
\text { ml/h or } \mu \mathrm{mol} / \mathrm{h}\end{array}$ & Control & Test & $p<$ \\
\hline \multicolumn{4}{|l|}{ Jcjunum $(40 \mathrm{~cm})$} \\
\hline \multicolumn{4}{|c|}{ Auranofin $(0 \cdot 2 \mathrm{mM}(\mathrm{n}=5)$} \\
\hline $\mathrm{H}_{2} \mathrm{O}$ & $2 \cdot 1 \pm(0 \cdot 5$ & $-0 \cdot 6 \pm 0 \cdot 4$ & 0.01 \\
\hline Mannitol & $1 \cdot 4 \pm 0 \cdot 5$ & $5 \cdot 3 \pm 2 \cdot 2$ & NS \\
\hline Auranofin & - & $2 \cdot 6 \pm 0 \cdot 4$ & - \\
\hline \multicolumn{4}{|c|}{ Auranofin $2 \mathrm{mM}(\mathrm{n}=6)$} \\
\hline $\mathrm{H}_{2} \mathrm{O}$ & $2 \cdot 3 \pm 0 \cdot 8$ & $-3 \cdot 2 \pm 0 \cdot 8$ & 0.001 \\
\hline $\mathrm{Na}^{+}$ & $121 \cdot 6 \pm 82 \cdot 2$ & $-536 \cdot 4 \pm 11 \cdot 9$ & 0.005 \\
\hline $\mathrm{K}^{+}$ & $0 \cdot 6 \pm 2 \cdot 3$ & $-28 \cdot 3 \pm 4 \cdot 5$ & 0.005 \\
\hline $\mathrm{Cl}^{-}$ & $247 \cdot 3 \pm 61 \cdot 5$ & $-129 \cdot 7 \pm 106 \cdot 4$ & 0.005 \\
\hline $\mathrm{HCO}_{3}^{-}$ & $-125 \cdot(0 \pm 32 \cdot 9$ & $-435 \cdot 0 \pm 96 \cdot 6$ & 0.05 \\
\hline Glucose $11.2 \mathrm{mM}$ & $218 \cdot 5 \pm 29 \cdot 6$ & $61 \cdot 4 \pm 13 \cdot 6$ & 0.005 \\
\hline Mannitol, $4 \mathrm{mM}$ & $-2 \cdot 4 \pm 1 \cdot 4$ & $8 \cdot 6 \pm 3 \cdot 6$ & 0.01 \\
\hline Auranofin & - & $64 \cdot 0 \pm 7 \cdot 3$ & - \\
\hline \multirow{2}{*}{\multicolumn{4}{|c|}{$\begin{array}{l}\text { Colon } \\
\text { Auranofin } 0 \cdot 2 \mathrm{mM}(n=6)\end{array}$}} \\
\hline & & & \\
\hline $\mathrm{H}_{2} \mathrm{O}$ & $0 \cdot 5 \pm 0 \cdot 2$ & $-1 \cdot 8 \pm 0 \cdot 6$ & 0.01 \\
\hline Mannitol & $-0 \cdot 1 \pm 0 \cdot 3$ & $3 \cdot 2 \pm 0 \cdot 9$ & 0.01 \\
\hline
\end{tabular}

Perfusion rate in the jejunum and colon was $0.7 \mathrm{ml} / \mathrm{min}$. Minus sign indicates net secretion. Data are mean \pm SE. Control and test solutions were perfused for two hours each in the sequence: control-test.

Table 2 Effect of 2 mM myochrysine on jejunal water and solute transport in the rat

\begin{tabular}{|c|c|c|c|}
\hline & \multicolumn{2}{|c|}{ Net transport ml/h or umol/h } & \multirow[b]{2}{*}{$p<$} \\
\hline & Control & Test & \\
\hline$\overline{\mathrm{H}_{2} \mathrm{O}}$ & $3 \cdot 0 \pm 0 \cdot 4$ & $4 \cdot 3 \pm 0 \cdot 4$ & 0.02 \\
\hline $\mathrm{Na}^{+}$ & $251 \cdot 4 \pm 41 \cdot 2$ & $434 \cdot 8 \pm 53 \cdot 6$ & 0.02 \\
\hline $\mathrm{K}^{+}$ & $6 \cdot 7 \pm 2 \cdot 3$ & $10 \cdot 4 \pm 2 \cdot 5$ & NS \\
\hline $\mathrm{Cl}^{-}$ & $337 \cdot 1 \pm 37 \cdot 8$ & $560 \cdot 8 \pm 52 \cdot 8$ & 0.005 \\
\hline $\mathrm{HCO}_{3}^{-}$ & $-78.9 \pm 8 \cdot 6$ & $-115 \cdot 6 \pm 27 \cdot 5$ & NS \\
\hline Glucosc, $11.2 \mathrm{mM}$ & $223 \cdot 1 \pm 13 \cdot 9$ & $235 \cdot 0 \pm 22 \cdot 6$ & 0.01 \\
\hline Mannitol, $4 \mathrm{mM}$ & $0 \cdot 1 \pm 0 \cdot 4$ & $3 \cdot 7 \pm 0 \cdot 8$ & 0.01 \\
\hline Myochrysine & - & $11 \cdot 6 \pm 1 \cdot 2$ & - \\
\hline
\end{tabular}

Data are mean $\pm S E$ from studies in six rats. Minus sign indicates net secretion. Control and test solutions were perfused for two hours each in the sequence: control-test.

Table 3 Effect of $0 \cdot 2 \mathrm{mM}$ Auranofin on mucosal c-AMP content

\begin{tabular}{llcl}
\hline \multicolumn{3}{c}{$\begin{array}{l}\text { Water movement } \\
\text { ml/hr }\end{array}$} & \\
\cline { 2 - 3 } & Control period & Test period & $\begin{array}{l}c-A M P \\
\text { pmollmg protein }\end{array}$ \\
\hline Control loop & $2 \cdot 4 \pm 0 \cdot 2$ & $2 \cdot 6 \pm 0 \cdot 3$ & $8 \cdot 9 \pm 0 \cdot 5$ \\
$\begin{array}{l}\text { Test loop } \\
\text { (Auranofin) }\end{array}$ & $1 \cdot 9 \pm 0 \cdot 1$ & $-0 \cdot 8 \pm 0 \cdot 4^{*}$ & $9 \cdot 5 \pm 0 \cdot 9$ \\
\hline
\end{tabular}

Data are mean $\pm S E$ from studies in four rats. Two adjacent $30 \mathrm{~cm}$ loops of intestine were perfused at $30 \mathrm{ml} / \mathrm{h}$. Control and test loops were perfused with two solutions each for two hours, in the sequence control-control or control-auranofin. Mucosal c-AMP content was determined at the end of the perfusion experiment. ${ }^{*} p<0.01 v$ control. was statistically significant in the colon $(p<0.01)$. Auranofin $(2 \mathrm{mM})$ induced water secretion $(\mathrm{p}<0.001)$ and electrolyte secretion $(p<0.05$ to $p<0.005)$, reduced the absorption of glucose $(p<0.005)$ and enhanced the absorption of mannitol $(p<0 \cdot 01)$. The fractional absorption of auranofin in the jejunum was $27 \cdot 8 \pm 4.3 \%$ during perfusion of $0.2 \mathrm{mmol} / \mathrm{l}$ and $75 \cdot 8 \pm 3 \cdot 5 \%$ during perfusion of $2 \mathrm{mmol} / \mathrm{l}(\mathrm{p}<0 \cdot 001)$. Polyethylene glycol recovery was $95.5 \pm 1.7 \%$ during the control period and $95 \cdot 1 \pm 1 \cdot 0 \%$ during perfusion with $2 \mathrm{mM}$ auranofin (NS).

\section{EFFECTS OF MYOCHRYSINE ON JEJUNAL}

TRANSPORT (Table 2)

In contrast with auranofin, myochrysine $(n=6)$ enhanced the absorption of water $(p<0.002)$, sodium $(p<0.02)$, and chloride $(p<0.005)$. Like auranofin it enhanced the absorption of mannitol $(p<0.01)$. The absorption rate of myochrysine was significantly less than that of auranofin $(\mathrm{p}<0 \cdot 001)$. Polyethylene glycol recovery was $103 \cdot 6 \pm 2 \cdot 0 \%$ during the control period and $109 \cdot 5 \pm 3 \cdot 4 \%$ during the test period (NS).

\section{EFFECT OF AURANOFIN ON MUCOSAL C-AMP (Table 3)}

Mucosal c-AMP levels were determined after perfusion of $0.2 \mathrm{mM}$ auranofin. Although auranofin induced water secretion $(\mathrm{p}<0.01)$ mucosal $\mathrm{c}$-AMP levels did not differ from those in the control loops.

\section{MORPHOLOGIC STUDIES}

Auranofin $(2 \mathrm{mM})$ causes severe mucosal damage characterised by loss of epithelial cells at the villus tips and infiltration with polymorphonuclear leukocytes (not shown). On scanning electron microscopy polymorphonuclear leukocytes and debris covered the villus tips (Figure). The changes observed after perfusion with $0.2 \mathrm{mM}$ auranofin appeared less severe, but no morphometric studies were done. In contrast with these findings, the villi appeared intact on light microscopy after perfusion with myochrysine. Scanning electronmicroscopy showed only occasional red blood cells at the tips of the villi.

\section{Discussion}

The data indicate that auranofin affects intestinal water transport adversely and that it has the potential to cause mucosal injury. The effect on water transport is dose dependent and present in the small and large bowel. The changes in water movement are associated with net secretion of $\mathrm{Na}, \mathrm{K}, \mathrm{Cl}$, and bicarbonate, reduction of glucose absorption and enhancement of mannitol absorption. Thus, the effects resemble those of certain dihydroxy bile acids and fatty acids on the intestine. " These in vivo 

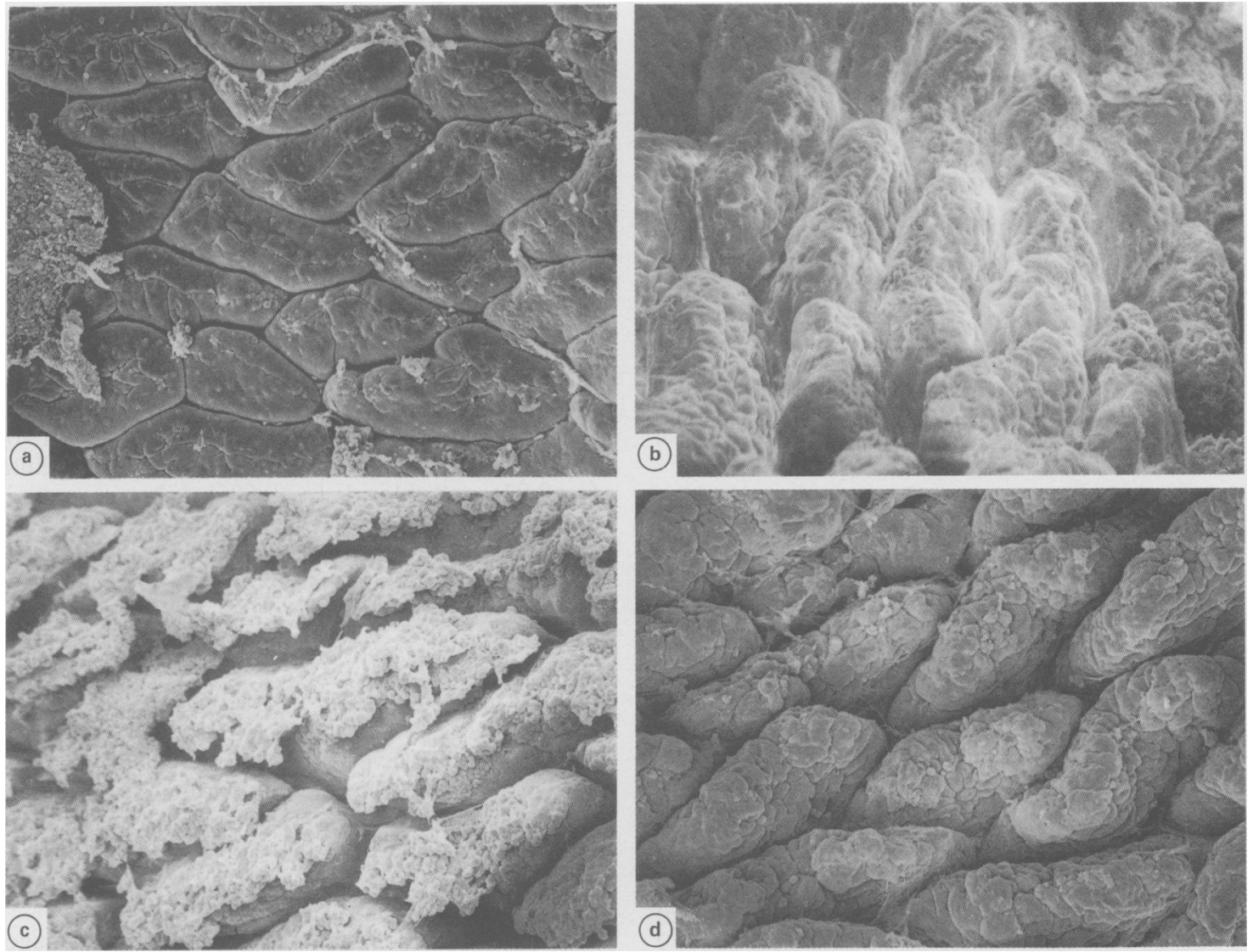

Figure Scanning electron microscopic appearance of rat jejunum after perfusion for 2 hours with control solution (a) (×200). 0.2 mM auranofin (b), $2 \mathrm{mM}$ auranofin (c) or $2 \mathrm{mM}$ myochrysine (d).

observations are in agreement with in vitro studies in the isolated rat intestine, where $0.147 \mathrm{mM}$ auranofin inhibited transport of glycine, galactose, sodium and water. $^{12}$ The current studies do not provide a definite answer about the mechanism responsible for these changes in intestinal electrolyte and water transport. The data indicate that the secretory effect is not mediated by c-AMP. The inhibition of glucose absorption could be secondary to an effect on active transport of glucose or caused by changes in mucosal permeability. The increased mannitol absorption suggests that mucosal permeability is enhanced by auranofin. ${ }^{3}$ Recently we have provided evidence which links inhibition of glucose absorption by bile acids to the combined effects of enhancement of mucosal permeability and fluid secretion." Enhancement of mucosal permeability alone, however, does not explain electrolyte and water secretion. Amphotericin $\mathrm{B}$, which also enhances mucosal permeability, stimulates absorp- tion of electrolytes glucose, ethylene glycols, and water in jejunal perfusion experiments. ${ }^{11+}$ The mechanism by which myochrysine enhanced the intestinal absorption of electrolytes, water and organic solutes remains unknown. The changes in mannitol absorption suggest that enhanced mucosal permeability may be responsible for this phenomenon.

The increase in fractional absorption of auranofin with increasing concentration in the perfusion solution is probably related to the fact that the compound increased mucosal permeability." We cannot, however, exclude the possibility that part of the 'enhanced absorption' may be the result of precipitation of the poorly soluble compound in the test segment during intestinal perfusion because only recovery of the compound in the effluent was determined. It is unlikely that adherence to the mucosa accounts for the observations because in this case one would expect a higher fractional loss of auranofin 
during perfusion with the solution containing the lower concentration of the compound. In vitro auranofin is absorbed by everted sacs of rat intestine and undergoes deacetylation in the process. ${ }^{15}$ The fact that myochrysine is poorly absorbed can be attributed to the greater polarity of this compound and to the fact that it is present in polymer form..$^{316}$

It is no surprise that auranofin caused mucosal injury because it has cytotoxic effects in tissue culture systems. ${ }^{17}$ In long term feeding experiments, auranofin caused gastric erosions and ileocaecal ulcers in rats. ${ }^{10}$ Thus, the observed injury should not be dismissed as the result of an artificially high concentration of auranofin in a supersaturated solution. Moreover, perfusion with $0.2 \mathrm{mM}$ auranofin also caused significant mucosal damage. Myochrysine had no effect on mucosal integrity. The reason for the difference in the effects of the two gold compounds is not readily apparent. Myochrysine may interact less readily with the enterocyte surface and have less access to the interior of the enterocytes because it is more polar and present in polymer form. ${ }^{3{ }^{16}}$ On the other hand the possibility that the injury is not an expression of gold toxicity but is caused by the structure of the carrier molecule cannot be excluded. We do not think, that taurocholate and lecithin in the auranofin solutions are responsible for these differences. Taurocholate $(10 \mathrm{mM})$ by itself has no effect on intestinal water transport in $\operatorname{man}^{19211}$ or experimental animals ${ }^{21}$ and lecithin blocks any possible adverse effects by bile acids. ${ }^{1022}$ We are not aware of any studies of gastric or intestinal morphology in patients receiving auranofin.

The purpose of the experiments was to determine whether auranofin has an effect on intestinal water and electrolyte transport. The observations show one possible mechanism for diarrhoea in patients receiving the drug. Other potential effects of auranofin which might contribute to diarrhoea, such as effects on intestinal motility or effects of auranofin metabolites on intestinal function, remain to be explored. Similarly, the possible modification of these effects by gastric, biliary, and pancreatic secretions will need to be evaluated. As the intraluminal concentrations of the drug in patients receiving auranofin are not known, it is not certain that the concentrations used in these perfusion experiments resemble those in the human intestine. Because only 15 to $30 \%$ of auranofin is absorbed and as the compound is poorly water soluble, it is, however, likely that it reaches the colon in concentrations close to its solubility limits. If $0.2 \mathrm{mM}$ auranofin can induce net fluid secretion in the colon, lower concentrations will be able to inhibit net water absorption. Under normal conditions about $2500 \mathrm{ml}$ of fluid enter the human colon in a 24 hour period. ${ }^{23}$ The colon reabsorbs $2300 \mathrm{ml}$, that is
$92 \%$. It takes only a reduction of the absorption rate from $92 \%$ to $84 \%$ to result in a fecal weight of $400 \mathrm{~g}$, which would be perceived as diarrhoea. Thus, much lower colonic concentrations of auranofin will suffice to cause diarrhoea. Clinical observations also suggest that the diarrhoea is caused by a direct effect of auranofin on the intestinal mucosa: there is no correlation between serum gold levels and the presence of diarrhoea ${ }^{24}$ diarrhoea and abdominal cramping are observed within three to four hours after ingestion of the drug ${ }^{24}$ and diarrhoea disappears with reduction of the dose or when the drug is administered in divided doses. ${ }^{25}$

This paper was presented in part at the annual meeting of the American Society for Clinical Investigation in Washington, DC, April 28, 1984 and published in abstract form in Clin Res 1984; 32: 537. This study was supported by Grant AM 17941 from the National Institute of Health, the Research Service of the Veterans Administration and by Smith, Kline and French, Laboratories, Philadelphia, PA.

\section{References}

1 Blodgett RC. Auranofin, experience to date. Am J Med 1983; 75: 86-9.

2 Delafuente JC, Osborn TG. Drug reviews: review of auranofin, an oral chrysotherapeutic agent. Clin Pharmacol 1984; 3: 121-7.

3 Furst DE. Mechanism of action, pharmacology, clinical efficacy and side effects of auranofin. Pharmacotherapy 1983; 3: 284-98.

4 Wingate DL, Sandberg RJ, Phillips SF. A comparison of stable and ${ }^{14} \mathrm{C}$-labelled polyethylene glycol as volume indicators in the human jejunum. Gut 1972; 13: 812-5.

5 Kobayashi Y, Maudsley DV. Practical aspects of double isotope counting. In: Bransome Jr ED, ed. Liquid scintillation counting. New York: Grune and Stratton, 1970: 76-85.

6 Wingate DL, Krag E, Mekhjian HS, Phillips SF. Relationships between ion and water movement in the human jejunum, ileum and colon during perfusion with bile acids. Clin Sci Molec Med 1973; 45: 593-606.

7 Harper JF, Brooker G. Femtomole sensitive radioimmunoassay for cyclic AMP and cyclic GMP after 2'0 acetylation by acetic anhydride in aqueous solution. J Cyclic Nucleotide Res 1975; 1: 207-18.

8 Lowry, OH, Rosebrough NJ, Farr AL, Randall RJ. Protein measurement with the Folin phenol reagent. J Biol Chem 1951; 193: 2265-75.

9 Wingate DL, Phillips SF, Hofmann AF. Effect of glycine-conjugated bile acids with and without lecithin on water and glucose absorption in perfused human jejunum. J Clin Invest 1973; 52: 1230-6.

10 Ammon HV, Thomas PJ, Phillips SF. Effects of long chain fatty acids on solute absorption: perfusion studies in the human jejunum. Gut 1977; 18: 805-13. 
11 Ammon HV, Walter LG, Loeffler RF. Effects of amphotericin $\mathrm{B}$ and cholera toxin on intestinal transport in the rat. J Lab Clin Med 102: 509-21.

12 Hardcastle J, Hardcastle PT, Kelleher DK. The effect of auranofin on intestinal transport mechanisms in the rat in vitro. [Abstract]. J Physiol 1984; 354: 86P.

13 Behrens R, Devereaux M, Hazleman B, Szaz K, Calvin J, Neale G. Investigation of auranofin-induced diarrhoea. Gut 1986; 27: 59-65.

14 Chen LC, Guerrant RL, Rohde JE, Casper AG. Effect of amphotericin B on sodium and water movement across normal and cholera toxin-challenged canine jejunum. Gastroenterology 1973; 65: 252-8.

15 Tepperman K, Finer R, Donovan S, et al. Intestinal uptake and metabolism of auranofin, a new oral goldbased antiarthritis drug. Science $1984 ; 225$ : 403-1.

16 Elder RC, Eidsness MK, Heeg MJ, Tepperman KG, Shaw CF, Schaeffer N. Gold-based antiarthritic drugs and metabolites. In: Lippard SJ, ed. Platinum, gold and other metal chemotherapeutic agents. Washington, D.C.: American Chemical Society, 1983; 209: 385-400.

17 Crooke ST, Mirabelli CK. Molecular mechanisms of action of auranofin and other cold complexes as related to their biologic activities. Am J Med 1983, 75: 109-13.

18 Payne BJ, Arena E. The subacute and chronic toxicity of SK\&F 36914, SK \& F D 39162 and gold sodium thiomalate in rats. Vet Pathol 1978; 15 suppl 5: 13-22.

19 Ammon HV, Thomas PJ, Phillips SF. Effects of oleic and ricinoleic acids on net jejunal water and electrolyte movement. J Clin Invest 1974; 53: 74-9.

20 Russell RI, Allan JG, Gerskowitch VP, Cochran KM. The effect of conjugated and unconjugated bile acids on water and electrolyte absorption in the human jejunum. Clin Sci Mol Med 1973: 45: 301-11.

21 Teem MV, Phillips SF. Perfusion of the hamster jejunum with conjugated and unconjugated bile acids: inhibition of water absorption and effects on morphology. Gastroenterology 1972; 62: 261-7.

22 Ammon HV. Effect of taurine conjugated bile salts with and without lecithin on water and electrolyte transport in the canine gallbladder in vivo. Gastroenterology 1979; 76: 778-83.

23 Debongnie JC, Phillips SF. Capacity of the human colon to absorb fluid. Gastroenterology 1978; 74: 698-703.

24 van Riel PLCM, Gribnau FWJ, van de Putte LBA, Yap $\mathrm{SH}$. Loose stools during auranofin treatment: Clinical study and some pathogenetic possibilities. $J$ Rheumatol 1983; 10: 222-6.

25 Bandilla K, Gross D, Dross W, et al. Oral gold therapy with auranofin (SK \& F-39162) - a multicentre open study in patients with rheumatoid arthritis. $J$ Rheumatol 1982; 9: suppl 8: 154-9. 